\title{
Clinical Trials Informatics System
}

National Cancer Institute

\section{Source}

National Cancer Institute. Clinical Trials Informatics System. NCI Thesaurus. Code C19991.

The Clinical Trials Information Management System is an effort to develop an integrated system for managing various aspects of a clinical trial. The overall goal of the project is to create an integrated tool to support all aspects of a clinical trial, including Protocol development/submission, Administration, Patient Management, and Data Collections and Acquisitions. 